\title{
Cognition of high-alert medication knowledge of clinical nurses and improvement measures to eradicate medication errors.
}

\author{
Liangrong Shen, Jinfeng Yan, Xia Xin, Zhongmin Sun* \\ The First Affiliated Hospital of Xi'an Jiaotong University, Shanxi Province, PR China
}

\begin{abstract}
Objective: To conduct survey on cognition of clinical nurses on knowledge of high-alert medication and propose relevant strategies for effective improvement.

Methods: One hundred twenty clinical nurses were randomly selected from medical staff in our hospital from July 2016 to February 2017, and the results were analyzed and evaluated by questionnaires.

Results: The results showed that, the total score of clinical nurses on knowledge of high-alert medication was 14-37 points, averaging $26.8 \pm 3.32$ points. The cognition of high-alert medication knowledge was significantly different among nursing staff with different age, service age, technical title and educational level $(\mathbf{P}<\mathbf{0 . 0 5})$.

Conclusions: It is necessary to establish a sound high-alert medication management system to master relevant knowledge, and reduce wrong medication by taking effective measures.
\end{abstract}

Keywords: Clinical nurses, High-alert medication, Awareness, Improvement measures.

Accepted on July 10, 2017

\section{Introduction}

In hospitals, a high error rate of medications can easily cause impact on patients. In United States, the ratio of personal injury caused by medication errors is reduced to less than $2 \%$ in the early stages. High-alert medication is a major factor in triggering events. According to the definition of medication by American Medical Safety Association, the medications that may cause serious injury or death to patients due to improper use are called high-alert medications. These kind of medications causes obvious injury with high probability of risks [1,2]. Compared with ordinary medications, the consequences of the disease will be more serious with errors in high-alert medications, which will possibly cause adverse consequences for patient's recovery. The use of medications has become a common event in clinical care that is prone to cause a risk in medication errors. Although relevant personnel have proposed the safety warning of high-alert medications, medical staff may not effectively avoid the medication errors from high-alert medications. A higher incidence of medication errors in the clinic may cause harm to the patients [3]. Therefore, nurses should pay proper attention to improve the mediation safety, especially the safety of high-alert medications.

Nurses should master the professional knowledge and technology skilfully, accumulate relevant experiences, and study the relevant knowledge and use of high-alert medications. In addition, nurses should enhance their cognition of high-alert medications to prevent the occurrence of adverse events [4]. Therefore, in this article, we analyzed the cognitive skills of clinical nurses on the knowledge of high-alert medications, to provide reasonable measures for improving clinical treatments.

\section{Data and Methods}

\section{General data}

During the period from July 2016 to February 2017, 120 nurses were selected randomly as subjects of the survey in this experiment. Patients selected had normal logic thinking ability and they were voluntary to accept questionnaires.

\section{Methods}

In this article, we used the questionnaire way. The questionnaires are designed according to the cognitive skills of clinical nurses on high-alert medications. By taking random cluster sampling method, all subjects were randomly selected from different departments with different ages and sexes. The questionnaires were released separately, including a total of 24 questions (single choice and multiple choices). A closed test was adopted, and all subjects answered questions in a fixed time under the guidance of site investigators and all answer sheets were taken back. The main contents included general information, knowledge of high-alert medications and if nursing staffs can accept relevant training, and the approach of needs. In addition, relevant reviews for improvement, etc. were also included. Finally a total of 120 questionnaires were recovered, with the recovery rate of $100 \%$. 


\section{Counter measures}

The cognition of the knowledge on high-alert medications by clinical nurses shows a significant decline, which has been in a dominant position in the medical and health service quality. As a prominent issue, it has become a major factor influencing social harmony and stability. Therefore, it is necessary to explore appropriate measures and put forward reasonable suggestions, so as to improve the cognition of high-alert medications [5-7].

\section{Hospitals}

Hospitals should establish a people-oriented concept and basis for better health services. Doctors should have good medical ethics and improve the medical service level with high satisfaction for patients and they should pursue superb medical skills to enhance medical service quality. The medical staff should have excellent professional knowledge and technical skills to reduce the frequency of accidents and win the patient's respect and trust. Therefore, love and responsibility are the job requirements. Medical institutions should further improve the construction management system of medical ethics and increase its supervision. In addition, they should resist the unwholesome social currents that have prominent problems and affect the medical circle, to establish the integrity concept of medical staff. If there are problems, they should be evaluated and treated according to the rules and regulations.

\section{Clinical nurses}

Clinical nurses should strengthen the learning of medical knowledge, follow the objective laws and seek truth from facts. They should learn to understand the high risk of medical treatment and adjust their emotions. When there is a contradiction, they should not avoid them but resolve through a calm communication between both parties. For the matters of principle, patient can solve them by seeking laws rather than using the means of violence. In some cases, because of the small age, relatively shorter experience, lower educational level and technical title, scores of related knowledge of highalert medications of clinical nurses are low. These conditions are directly related to the lack of clinical experience and lack of relevant knowledge system training, so they should continue to strengthen training and learning.

\section{Management of high-alert medications}

The management of high-alert medications should stress the injuries to patients caused by improper use of medications. The supervision should focus on the use of medications within the medical institutions. In daily nursing work, lack of comprehensive cognition of the high-alert medication is a major defect of the management, which will produce safety risks on themselves. Related studies have revealed that the nurse's inadequate knowledge on the use of medications and lack of skills will be directly associated with the occurrence of adverse events. The management of high-alert medications is a new concept and new difficulty in the clinical nursing management work. The traditionally defined special drug management mainly stresses the management according to law and reasonable use. However, the use of high-alert medications has no fixed use dose and the safety index is relatively narrow. If this kind of medications are used unreasonably, serious consequence will happen which will seriously threaten the lives of patients. Studies have reported that more than half of life-threatening factors in the medication are directly associated with the rapid rate of drug infusion.

\section{Government departments}

Government departments should accelerate the establishment and improvement of the basic medical insurance of urban residents, the cooperative medical system of rural residents and the medical assistance mechanism of special difficulty groups. The government should increase the investment on medical and healthcare and implement fundamental reforms of the existing medical system. Medical resources allocation should be reasonable and the construction of medical security system should be strengthened to achieve universal health insurance coverage. The medical insurance funds are established, and the expense of medical insurance is collected from the state, entities and individuals, to curb the sharp rise in medical expenses for better medical services, to benefit all people.

\section{Results}

\section{Survey results of clinical nurses}

The survey results of clinical nurses were shown in Table 1.

Table 1. General information of clinical nurses.

\begin{tabular}{|c|c|c|}
\hline Item & Number of nurses & Ratio (\%) \\
\hline \multicolumn{3}{|l|}{ Sex } \\
\hline Male & 11 & 9.17 \\
\hline Female & 109 & 90.83 \\
\hline \multicolumn{3}{|l|}{ Age } \\
\hline$<30$ & 15 & 12.5 \\
\hline $30-40$ & 82 & 68.33 \\
\hline$>40$ & 23 & 19.17 \\
\hline \multicolumn{3}{|l|}{ Educational level } \\
\hline Bachelor or below & 112 & 93.33 \\
\hline Master or above & 8 & 6.67 \\
\hline \multicolumn{3}{|l|}{ Service years } \\
\hline$<5$ & 79 & 65.83 \\
\hline $5-10$ & 25 & 20.83 \\
\hline$>10$ & 16 & 13.33 \\
\hline
\end{tabular}

Technical title 


\section{errors}

\begin{tabular}{lcc}
\hline Primary level & 64 & 53.33 \\
\hline Middle level and above & 56 & 46.67 \\
\hline Hospital rules and regulations & & \\
\hline Yes & 81 & 67.5 \\
\hline No & 39 & 32.5 \\
\hline Prescription contact or not & & \\
\hline Yes & 77 & 64.17 \\
\hline No & 43 & 35.83 \\
\hline
\end{tabular}

\section{The knowledge of clinical nurses on high-alert medications}

The total scores of the high-alert mediation related knowledge for 120 clinical nurses were $14-37$ points, average of $26.8 \pm$ 3.32 points. The cognition of clinical nurses on the high-alert mediation related knowledge was shown in Table 2.

Table 2. The cognition of clinical nurses on the high-alert mediation related knowledge.

\begin{tabular}{|c|c|c|c|}
\hline Item & Number of nurses & Score & $P$ value \\
\hline \multicolumn{4}{|l|}{ Sex } \\
\hline Male & 11 & $26.60 \pm 3.12$ & $>0.05$ \\
\hline Female & 109 & $28.31 \pm 3.50$ & \\
\hline \multicolumn{4}{|l|}{ Age } \\
\hline$<30$ & 15 & $17.6 \pm 2.96$ & $<0.05$ \\
\hline $30-40$ & 82 & $23.8 \pm 3.11$ & \\
\hline$>40$ & 23 & $25.3 \pm 3.02$ & \\
\hline \multicolumn{4}{|l|}{ Educational level } \\
\hline Bachelor or below & 112 & $19.7 \pm 3.65$ & $<0.05$ \\
\hline Master or above & 8 & $26.4 \pm 4.02$ & \\
\hline \multicolumn{4}{|l|}{ Service years } \\
\hline$<5$ & 79 & $20.01 \pm 3.34$ & $<0.05$ \\
\hline $5-10$ & 25 & $25.8 \pm 3.48$ & \\
\hline$>10$ & 16 & $27.4 \pm 2.88$ & \\
\hline \multicolumn{4}{|l|}{ Technical title } \\
\hline Primary level & 64 & $26.9 \pm 3.24$ & $<0.05$ \\
\hline Middle level and above & 56 & $31.9 \pm 3.55$ & \\
\hline \multicolumn{4}{|c|}{ Hospital rules and regulations } \\
\hline Yes & 81 & $28.7 \pm 4.03$ & $<0.05$ \\
\hline No & 39 & $24.1 \pm 3.62$ & \\
\hline \multicolumn{4}{|l|}{ Prescription contact or not } \\
\hline Yes & 77 & $32.5 \pm 4.11$ & $<0.05$ \\
\hline
\end{tabular}

№ $43 \quad 28.6 \pm 3.72$
$\begin{aligned} & \text { Approaches for knowledge of high-alert medications } \\ & \text { for clinical nurses }\end{aligned}$

The different approaches for high-alter medication knowledge by clinical nurses are listed in Table 3 .

Table 3. Approaches for knowledge of high-alert medications for clinical nurses.

\begin{tabular}{ll}
\hline Approach & Number of cases (n) \\
\hline Publicity & $61(50.8 \%)$ \\
\hline Books and journals & $74(61.7 \%)$ \\
\hline Media network and reports & $38(31.7 \%)$ \\
\hline Seminars & $98(81.7 \%)$ \\
\hline
\end{tabular}

\section{Discussion}

High-alert medications refer to those medications with significant pharmacological effects and rapid effect in clinical practices that easily cause harm to human body due to improper use. This mainly includes high-concentrations of electrolyte preparations, muscle relaxants and cytotoxic drugs, etc. Clinical care has high risk due to direct implementation of a class of high-alert medications. Clinical nurses have inconsistent cognition of the high-alert medications, therefore, to know the related knowledge of high-alert medications, cognition attitude and ability to deal with events and enhance the management of high-alert medications, improving the quality of care for patients are the major key aspects [8]. In order to ensure that the treatment can be carried out smoothly and feel responsible for the safety of patient's life, it is necessary to guarantee the preparation works of high-alert medications, and regulate them reasonably. The premise for the best opportunity of treatment is to guarantee the correct use, orderly management and preparation of medications in clinic; and it is also an important guarantee for pre-hospital saving of patient's life and more standardized management, to improve the care [9].

The results of this survey showed that the total score of clinical nurses for the knowledge of high-alert medication was 14-37 points, with an average of $26.8 \pm 3.32$ points. The cognition of high-alert medication knowledge was significantly different among nursing staff with different age, service age, technical title and educational level $(\mathrm{P}<0.05)$.

In summary, the smooth implementation of clinical treatment is largely dependent on the standardized management of drugs. Therefore, it is necessary to strengthen the training in the standardized management work. In the implementation of standardized management, it is required to carry out discussion strategies and analyze the major problems, propose the views for management improvement according to the management condition of goods. The management should guarantee to 
enhance the enthusiasm and initiative of individuals, and allow everyone to participate in the management work.

\section{References}

1. Ji L, Fan YY, Hu W. Affecting factors of nursing staff's knowledge level on high-alert medications. Chin Nurs Manag 2015; 15: 1107-1110.

2. Lan BE, Mou P. Exploration of management model of highalert medications. Chin Licensed Pharm 2013; 12: 41-47.

3. Yang Y, Jiang JF, Cui ZM. Survey on cognition of highalert medications of medical staffs in a hospital. Chin J Hosp Administration 2012; 28: 690-694.

4. Yang WH, Zhao L, Wu YL. Analysis on influencing factors of junior paediatric nurse's cognition of intravenous infusion of high-alert medications. Chin Nurs Res 2015; 29: 3762-3765.

5. Li GZ, Wu LM, Chen YM. Understanding of basic knowledge of high-alert medications for junior nurses and countermeasures in primary hospitals. Nurs Rehabil J 2012; 11: 311-315.

6. Wu YX, Zheng AL, Feng JW. Analysis on influencing factors of nurse's cognition of intravenous infusion of high- alert medications in primary hospitals. Nurs Rehabil J 2014; 13: 535-540.

7. Li GZ, Wu LM, Li LJ. Analysis on intravenous infusion risks of junior pediatric nurses and prevention measures in primary hospitals. Nurs Rehabil J 2013; 12: 276-278.

8. Li Y, Li SL, Zhao LL. Influence of training on nurse's cognition of high-alert medications. J Qilu Nurs 2014; 20: 113-116.

9. Zhu YG. Investigation on awareness of high-alert medications in medical staffs. Cent South Pharm 2014; 12: 596-599.

\section{*Correspondence to}

Zhongmin Sun

The First Affiliated Hospital of Xi'an Jiaotong University

Shanxi Province

PR China 